\title{
Exploration of Construction and Management Mode for Forest Natural Reserve
}

\author{
Yinghua Luo ${ }^{1}$, Shaoguo Long ${ }^{2}$ \\ ${ }^{1}$ Forestry College, Guangxi University, Nanning, 530004, China \\ ${ }^{2}$ Guangxi Daming Mountain National Nature Reserve Authority, Nanning, 530023, China
}

\begin{abstract}
Keywords: Forest natural reserve. Prominent problem. Construction and management. Protection and development
\end{abstract}

\begin{abstract}
The main purpose of building the forest reserve is to protect forest resources and create better environment for human beings to study plants and rationally utilize natural resources. As the era develops, human begins gradually form the awareness of natural protection and increasingly realize the forest is an important part of earthly environment. It is required to combine activities of forest resource protection with human production development. But, many problems exist in construction and management of forest natural reserve. These problems restrict construction and management of the protection areas and give rise to inconvenience to life of local people. Thus, it is required to combine protection and development under the principle of sustainable development so as to drive further development of construction and management of forest natural reserve.
\end{abstract}

\section{Foreword}

Forest resources are important natural resources owned by human beings and are closely related to human survival and development. Owning rich forest resources and developed forestry is the significant mark of state richness, national prosperity and social civilization worldwide. However in China, economic development for a long time is based on environmental destruction. The forest is cut down excessively and natural forest land is occupied in quantity. Currently, primitive and natural forest reduces day by day and is on the verge of exhaustion. To protect forest resources, take full advantage of the research value of forest resources, explore natural evolvement rule of the forest and efficient ways to rationally utilize forest, animal and plant resources, it is required to accelerate construction of forest natural reserve, improve energetically management level and better give play to the effects of forest natural reserve.

\section{Main problems in construction of China's forest natural reserve}

\section{Fast construction speed and small management force}

China increases certain input in construction of forest natural reserve. The speed of construction of forest natural reserve increases. But, poor management occurs. Such practice of paying attention to quantity and neglecting quality will make construction of forest natural reserve formalized, which is to the disadvantage of protection of China's forest resources. Different situations exist in different regions. The overall level is uneven. Many regions have dome a lot for construction of forest natural reserve, but fail to pay enough attention to management of the reserve. Thus, some hidden dangers are left. These phenomena are mainly reflected in the following aspects: firstly, construction of the reserve is not well implemented in pace. Many forest natural reserves have problems in setup of management departments. The expenditure and personnel arrangement are restricted during startup for the organization. There is no professional forest administrator and lack of institutional framework. The guiding function of the documents of the government cannot work. After the management organization is set up, management still lacks. Secondly, the construction does not comply with standards. During construction of forest natural reserve, especially in the construction process of city-level and county-level protection areas, there is no standardized identification for the boundary of natural reserve. Besides, there is no public announcement on public platform. Local people do not 
know the protection range of natural reserve. Sometimes, after some natural protection areas are constructed, local people fail to realize them. Thus, there is no guarantee for protection of forest resources. Thirdly, management of natural reserve is disconnected with local concrete conditions. In many forest natural reserves, economic development is poor. For a long time, restricted by input force, there are many management loopholes in the protection areas. Many forests are still cut down. Thus, forest resource management cannot be cooperated with life of local people. Thus, management efficiency reduces. Due to the lack of corresponding personnel and special funds, most forest natural reserves cannot carry out research work normally. There is also no efficient mode in terms of resource utilization. Thus, it is hard to give play to the function of forest natural reserve and the construction requirements cannot be met, either. The function of protection of forest resources is not exerted. This lacks practical significance.

\section{Lack of special funds input}

Main fund source of local forest natural reserve is local financial budget. In most provinces, the expenditure of the personnel in provincial forest natural reserve is from provincial financial budget. But for low-level forest natural reserve, national special fund input is very short. It is event difficult to support remuneration of related personnel. According to the purpose, national funds can be classified into infrastructure fund, daily operation fund and special project fund. Infrastructure fund accounts for the largest proportion in the expenditure and is generally used in construction of daily work and characteristic tourist facilities as well as traffic construction. Most daily operation funds are used for the wage of personnel in the forest reserve and daily office expenses. Special project fund may be used survey of the resource in the natural reserve or other short-term projects. With regard to job arrangement for daily fire protection inspection and data monitoring of the forest natural reserve, many natural reserves have no special fund investment plan. The funds for this part are very important and the foundation of protection of forest resources. It can be seen from such situations that most forest natural reserves are restricted by fund shortage so that there is lack of fire protection inspection and data control and organization in daily work. Some forest natural reserves with high value will receive international funds. Such funds have one-off or unconventional features and are mainly used for promotion of overall work level of administrators of the reserves, investigation and statistics of forest resources and publicity of fire protection awareness. But such fund source is unstable. Besides, such funds generally have special purpose. Long-term fund shortage cannot be solved fundamentally. In practical work, infrastructure construction is often prior to the input in daily work. In current fund use management, infrastructure construction of forest natural reserve is stressed. Daily protection, monitoring and management are neglected. This is one of the important causes why management level of forest natural reserve improves slowly under current situations. After the funds are allocated to the management department of the reserve, supervision of fund management and use is insufficient. The phenomena of unreasonable fund allocation occur occasionally. The fund use is not allocated rationally. The fund is not used to ensure daily work with pertinence. The plight of insufficient expenditures for administrators must be encountered. Thus, natural reserves start to consider gaining the funds by use of the protected resources. Usual situation is as follows: ecological resources are excessively developed for ecological tourism; environment in the forest reserve degrades; this violates original intention of setup of forest natural reserve.

\section{Prominent land ownership dispute and community contradiction}

Chinese existing land ownership legislation for natural reserve fails to consider problems comprehensively while stressing natural conservation. The natural reserve does not purely isolate a zone with human production and life. This neglects economic function of the land and does not protect production and life of local residents. Before the natural reserve is build, original residents in the region have property attribute for the land legally. The provisions without thorough consideration are prepared to directly intervene or explicitly prohibit pasturing, forest cutting, medicinal material collection, wildlife hunting, crop planting, wildlife taming and breeding, which seriously affects people's life and does not comply with social operation to some extent. These measures fail to combine local actual conditions and encounter many barriers in actual work so that infringement activities and related conflicts occur. 


\section{Construction and management of forest natural reserve}

\section{To strengthen scientific planning and management}

To strengthen construction and management of forest natural reserve can effectively protect forest resources. Growing environment of trees can be ensured through ecological functional protection. Governments at all levels and management departments of forest natural reserves should unite related departments such as State Development and Reform Commission, fiscal management departments, scientific research institutes and personnel management departments to improve construction and management level of forest natural reserves fundamentally. Firstly, each department should pay attention to environment-related work, coordinate and cooperate mutually to put management work into practice and jointly drive better and faster development of construction of forest natural reserve. Besides, the great international influence of forest resources should be exerted. It is required to enhance communication and cooperation with foreign protection zone construction units, introduce advanced techniques and management methods, establish and perfect management system as well as promote management level. Under the guidance of development planning outline of China's natural reserve and Development planning of natural reserves prepared by each province, autonomous region and municipality, it is required to combine economic development level of the reserve to prepare plans for forest natural reserve according to actual conditions. Before the plan is prepared, it is necessary to carry out detailed investigation and statistics of main influence factors in the region and make scientific analysis and ensure the rationality of natural reserve planning in combination of overall situations of economic and social development of the state and provinces. In addition, it is required to enhance supervision and completely eradicate blind construction and insufficient management in the construction process.

\section{To increase special fund input}

To do construction and management of forest natural reserve well, the core is to coordinate the relationship between protection and development. Low economic development level is one of main causes of resource abuse. If the protection is regarded as the core and development importance is neglected in work, it is hard to promote sustainable development of the reserve. Fund allocation for construction and management of forest natural reserve is uniformly arranged by financial budget departments of people's governments at each level. These funds belong to the input in social development planning. Resource allocation should be optimized in fund arrangement for forest natural reserve. National and local administrative departments concerned should make plans for special funds according to the development direction of the project and reserve funds for key works. The state should further increase the supply of development and construction of forest natural reserve and ensure construction and management quality. Moreover, it is required to mobilize positive factors and seek more diversified fund raising channels. Since forest protection is value by many countries, international exchange and cooperation can be enhanced. Besides, it is necessary to strive for financial aid for forest natural reserve from international environmental protection organizations, foreign governments and foundations devoted to maintaining ecological balance. National and regional governments should consider the life and development of local residents during environmental protection in the process of establishment and planning of the reserve. Meanwhile, National and regional governments should carry out scientific survey and analysis, formulate supporting development plan and promote joint development of environmental protection and economy, such as increasing fund support in the reserve and especially remote mountain areas, so as to ensure local economic development and the improvement of living standard of local people and create conditions for giving play to the functions of the reserve.

\section{To enhance publicity of the importance of building forest natural reserve}

To enhance publicity of environmental protection and improve environmental awareness of the whole society is the foundation of construction of forest natural reserve. Enhancement of construction and management of the reserve can protect national important resources and maintain national ecological resources. Meanwhile, China can build good international image of responsible great power. So, it is required to conduct vigorous propaganda of the importance of construction of forest 
natural reserve through public platforms with wide coverage, guide tourism ecologicalization and communicate environmental protection idea in combination of beautiful natural scenery and environmental protection with tourists as the carrier. It is required to enhance international la communication and foreign publicity of forest natural reserve and make construction achievements of forest natural reserve in China approved by other countries in the world. In addition, better internal environment should be created for introducing new techniques and striving for funds for construction and management of forest natural reserve.

\section{To combine environmental protection and cultural protection}

During building forest natural reserve, it is required to regard improving the living quality of local residents and protecting local culture as the important issues. Ecological environmental protection and humanistic culture inheritance can be considered simultaneously only through changing traditional ideas and giving play to the leading role of people. It is required to actively collect, protect and generalize experience and ecology knowledge of harmonious coexistence between human and nature and combine biodiversity protection with science ands traditional life knowledge and continue means of livelihood and ideas beneficial to ecological protection so as to product cultural diversity. In addition, it is required to value the production and living knowledge of local people, especially give play to the important functions of the spirit and experience of resisting against bad natural environment and poor economic situation in forest eco-tourism development and realize the objective of improving tourists' awareness of ecological environmental protection during participation in tourism and benefiting from development of tourism for local people.

\section{Conclusions}

The purpose of setting up of forest natural reserve is to protect forest resources and natural environment. It is also required to attach importance to scientific research value of forest vegetation on the basis of protection of natural environment, study growth law of trees and their adaptation to environment so as to find the way to rationally utilize forest resources. In the new era, the idea of construction natural reserve should be changed. The function of local people in the reserve should be exerted. It is required to combine production and life with natural protection with people as the subject. It is required to ensure sufficient funds for forest natural reserve through economic development and promote rapid and healthy economic development through environmental protection. It is also continuously detail construction and management of forest natural reserve to drive overall development of society and economy.

\section{References}

[1] Liu Chenglin: Current situation and analysis of type and structure of China's natural protection areas, Journal of Nanjing Forestry University (natural science), 2008(32)

[2] Wang Changhai, Wen Yali: Study on countermeasures to manage nature protection area from the perspective of externality of public goods, Reformation \& Strategy, 2011(03)

[3] Wang Xiaohui, Liu Hui, Ge Jing: Problems and countermeasures for construction and development of natural protection areas in Anhui province, Journal of Anhui University (natural science), 2011(04)

[4] Meng Qingyu, Liao Xiuchuan: On construction and sustainable development of China's natural protection areas, Journal of Xichang College (natural science), 2011(04)

[5] Zhou Li, Chen Xiaoqian, Wu Chengliang: Effects of land ownership on China's natural protection areas, Journal of Beijing Forestry University (natural science), 2009(04)

[6] Zhang Guangyue, Hou Changyi: On type and feature of forest natural reserve, Technological Pioneers, 2012(08) 